\title{
Nutritional Assessment of Adult Cancer Patients admitted at the Philippine General Hospital using the Scored Patient Generated Subjective Global Assessment Tool (PG-SGA)
}

\author{
Carmela Isabel A. Caballero, ${ }^{1}$ Marie Carmela M. Lapitan ${ }^{1,2}$ and Brian S. Buckley ${ }^{1}$ \\ ${ }^{1}$ Department of Surgery, College of Medicine and Philippine General Hospital, University of the Philippines Manila \\ ${ }^{2}$ National Institutes of Health, University of the Philippines Manila
}

\begin{abstract}
Objectives. Malnutrition is common among cancer patients. The aim of this study was to determine the nutritional status of preoperative cancer patients upon admission at a tertiary hospital in the Philippines. It also aimed to identify common symptoms with adverse impact on nutrition and to correlate the nutritional status to the length of hospital stay and development of post-operative complications.
\end{abstract}

Methods. A hospital-based prospective cohort study design was conducted among pre-operative adult cancer patients admitted from September to December 2010. Nutritional status assessment was done using the Scored Patient-Generated Subjective Global Assessment (PG-SGA) tool and correlation to their symptoms, length of hospital stay, and post-operative complications were determined using analysis of variance (ANOVA) and Chi-Square tests.

Result. A total of 103 patients were included for the study amongst whom prevalence of malnutrition was $83 \%$. Symptoms that were significantly associated with severity of malnutrition were early satiety, lack of appetite and alteration in taste perception. Poor nutritional status was associated with increased mean length of hospital stay: 7.5, 14.1 and 15.1 days for wellnourished, moderately malnourished and severely malnourished, respectively ( $p=0.048)$.

Conclusion. Using the Scored PG-SGA tool, this study observed a correlation between severity of nutritional status and increased length of hospital stay among cancer patients. Presence of nutritional impact symptoms such as lack of appetite, early satiety, and alteration of taste perception correlated with the degree of malnutrition on admission.

Poster presented at the European Society of Parenteral and Enteral Nutrition Congress (ESPEN), September 8-11, 2012, Barcelona, Spain.

Corresponding author: Carmela Isabel A. Caballero, MD

Clinical Research Fellow for Surgery

European Organization for the Research and Treatment of Cancer

Avenue Emmanuel Mournier, 83 / 111200 Brussels, Belgium

Telephone: +32 27741611

Email: caballero.surgery@gmail.com
Recommendations. Formal objective assessment of the nutritional status of cancer patients should be done. Addressing the symptoms of lack of appetite, early satiety, and alteration of taste perception should be prioritized to prevent deterioration in nutrition.

Key Words: Scored PG-SGA, nutritional status assessment, cancer malnutrition

\section{Introduction}

Malnutrition is commonly associated with cancer and adversely affects the quality of life and survival of patients. It is caused by a variety of factors, including decreased food intake, adverse effects from anticancer treatment, and wasteful metabolic processes. ${ }^{1}$ The global prevalence of malnutrition ranges from $30 \%$ to $85 \%$ and is most common in patients with gastric, pancreatic, lung, prostate and colon cancer. ${ }^{2}$ Severity of malnutrition on hospital admission is known to be a strong predictor of length of hospital stay, increased hospital costs and increased risk for morbidity and mortality. Despite the recent advances in cancer diagnosis and treatment, malnutrition continues to be prevalent and difficult to reverse. Recent data shows that malnutrition is an independent risk factor with a significant effect on the important clinical parameters of morbidity, mortality, complication rates, length of hospital stay, quality of life, tolerance to treatment and prognosis. ${ }^{3}$

Almost $30 \%$ of surgical admissions at the Philippine General Hospital (PGH), a tertiary public hospital, are cancer patients. ${ }^{4}$ However, formal nutritional assessment is not routinely done for these patients. This prospective cohort study aimed to determine the nutritional status of preoperative cancer patients upon admission at PGH using a validated nutritional assessment tool, the Scored Patient Generated - Subjective Global Assessment (PG-SGA). ${ }^{5}$ It also aimed to identify common symptoms with adverse impact on nutrition and to assess to what degree the nutritional status of cancer patients is associated with the length of hospital stay and development of post-operative complications. 


\section{Methods}

\section{Study design and population}

A prospective cohort study assessed the nutritional status of pre-operative adult cancer patients admitted to the Philippine General Hospital from September to December 2010, their nutritional symptoms, and the relationship of their nutritional status to the length of hospital stay and the development of post-operative complications.

Men and women $\geq 18$ years old who were admitted to Philippine General Hospital from September to December 2010 with tissue diagnosis of cancer and who were scheduled for palliative or definitive surgery or for neoadjuvant chemotherapy or radiotherapy were included in the study. Patients with solid tumors of the head and neck, breast, colorectal, hepatobiliary, genitourinary, and upper gastrointestinal tract were included. The study did not include those with gynecological, lung and hematological cancers. The protocol was approved by the Philippine General Hospital Expanded Hospital Review Office Ethics Committee and performed in compliance with the principles of the Declaration of Helsinski. The Philippine General Hospital is a tertiary public hospital with a 1,439 bed capacity, where surgical cases are estimated to be at least $25 \%$ of all the admissions in the hospital.

The calculated sample size for the study was 98 based on a $50 \%$ prevalence of malnutrition among cancer patients, ${ }^{6}$ a desired spread of $+/-10 \%$, and a $95 \%$ confidence interval and a power of $80 \%$.

\section{Data collection}

Eligible patients were identified through daily review of ward reports and the electronic database of the Department of Surgery. Once informed consent for participation had been obtained, the patients were interviewed and examined using the scored PG-SGA tool within 24 to 48 hours of admission. Baseline data collection also included age, gender, cancer type and stage, presence of ostomies, use of neoadjuvant chemotherapy or radiotherapy, and the presence of infection in the last six months.

The scored PG-SGA is a modification of the Subjective Global Assessment (SGA) used in the assessment of nutritional status in cancer patients. ${ }^{5}$

The first part of this tool is a medical history which includes questions regarding the patient's general profile, history of weight loss, food intake, and daily activity. Symptoms with adverse effect on nutrition were also noted. Each symptom was scored according to its severity. Subsequently, the researcher performed a physical examination. Weight in kilograms was taken within 24 hours of admission. Evaluation of the muscle status was done by grading the degree of wasting of the temporalis muscle, clavicles, shoulders, interosseous muscles, scapula, thigh and calves. Evaluation of the fat stores was done by inspection of the orbital fat pads, triceps skin fold and fats overlying the $6^{\text {th }}$ to $12^{\text {th }}$ ribs. Lastly, evaluation of fluid status was done by checking for presence of edema of the ankles and sacrum, and for ascites. Corresponding scores were given based on the prescribed system of the tool. The total scores of the history and physical examination were used to determine the nutritional triage recommendations of the patients. The nutritional status of the patient was based on the global assessment categorization portion of the tool, which considers weight, nutrient intake, nutritional impact symptoms, functioning and physical examination (Table 1).

Table 1. PG-SGA Global Assessment Categories of Nutritional Status

\begin{tabular}{|c|c|c|c|}
\hline Category & $\begin{array}{c}\text { Stage A } \\
\text { Well } \\
\text { Nourished }\end{array}$ & $\begin{array}{c}\text { Stage B } \\
\text { Moderately } \\
\text { nourished or } \\
\text { suspected } \\
\text { malnutrition }\end{array}$ & $\begin{array}{c}\text { Stage C } \\
\text { Severely } \\
\text { malnourished }\end{array}$ \\
\hline Weight & $\begin{array}{l}\text { No wt loss } \\
\text { OR recent } \\
\text { non-fluid wt } \\
\text { gain }\end{array}$ & $\begin{array}{l}\sim 5 \% \text { wt loss within } 1 \\
\text { month (or } 10 \% \text { in } 6 \\
\text { months) OR No wt } \\
\text { stabilization or wt } \\
\text { gain (i.e. continued wt } \\
\text { loss) }\end{array}$ & $\begin{array}{l}>5 \% \text { wt loss in } \\
1 \text { month (or } \\
>10 \% \text { in } 6 \\
\text { months) OR } \\
\text { No wt } \\
\text { stabilization or } \\
\text { wt gain (i.e. } \\
\text { continued wt } \\
\text { loss) }\end{array}$ \\
\hline $\begin{array}{l}\text { Nutrient } \\
\text { Intake }\end{array}$ & $\begin{array}{l}\text { No Deficit } \\
\text { OR } \\
\text { Significant } \\
\text { recent } \\
\text { improvement }\end{array}$ & $\begin{array}{l}\text { Definite decrease in } \\
\text { intake }\end{array}$ & $\begin{array}{l}\text { Severe deficit } \\
\text { in intake }\end{array}$ \\
\hline $\begin{array}{l}\text { Nutrional } \\
\text { Impact } \\
\text { Symptoms }\end{array}$ & $\begin{array}{l}\text { None OR } \\
\text { Significant } \\
\text { recent } \\
\text { improvement } \\
\text { allowing } \\
\text { adequate } \\
\text { intake }\end{array}$ & $\begin{array}{l}\text { Presence of nutritional } \\
\text { impact symptoms }\end{array}$ & $\begin{array}{l}\text { Presence of } \\
\text { nutrition } \\
\text { impact } \\
\text { symptoms }\end{array}$ \\
\hline Functioning & $\begin{array}{l}\text { No deficit OR } \\
\text { significant } \\
\text { recent } \\
\text { improvement }\end{array}$ & $\begin{array}{l}\text { Moderate functional } \\
\text { deficit OR Recent } \\
\text { deterioration }\end{array}$ & $\begin{array}{l}\text { Severe } \\
\text { functional } \\
\text { deficit or } \\
\text { recent } \\
\text { significant } \\
\text { deficit }\end{array}$ \\
\hline $\begin{array}{l}\text { Physical } \\
\text { Exam }\end{array}$ & $\begin{array}{l}\text { No deficit OR } \\
\text { Chronic } \\
\text { deficit but } \\
\text { with recent } \\
\text { clinical } \\
\text { improvement }\end{array}$ & $\begin{array}{l}\text { Evidence of mild to } \\
\text { moderate loss of } \\
\text { subcutaneous fat } \\
\text { and/or muscle mass } \\
\text { and/or muscle tone on } \\
\text { palpation }\end{array}$ & $\begin{array}{l}\text { Obvious signs } \\
\text { of malnutrition } \\
\text { (e.g. severe } \\
\text { loss of } \\
\text { subcutaneous } \\
\text { tissue, } \\
\text { possible } \\
\text { edema) }\end{array}$ \\
\hline
\end{tabular}

When compared with other assessment tools such as the Mini-Nutritional Assessment (MNA), the scored PG-SGA has the advantage of being more sensitive and specific in detecting malnutrition among cancer patients as well as 
acute changes in their nutritional status. ${ }^{7}$ Whereas the original scored PG-SGA tool was designed to have patients accomplish the first four components, a trained research assistant administered these components through an interview for this study.

After the nutritional assessment, each patient was followed up and the timing of their definitive surgery, emergence of post-operative complications and the date of discharge were recorded. Post-operative complications were classified as minor (health-care associated pneumonia, urinary tract infection and superficial surgical site infections) and major (bleeding, anastomotic leak, deep surgical site infections, death). Outcome measures in this study included the correlation of the nutritional status, nutritional impact symptoms, post-operative complications, and length of hospital stay.

\section{Statistical Analysis}

Continuous variables (length of hospital stay, age) were expressed as mean $\pm \mathrm{SD}$ and the categorical variables (gender, cancer type and stage, preoperative use of chemoradiotherapy, presence of infection pre-operatively, presence of ostomies, nutritional status, presence of major and minor complications post-operatively) as counts and percentages. Distribution of continuous variables (age, length of hospital stay, between PG-SGA rating groups was considered using analysis of variance (ANOVA) tests. Distribution of dichotomous variables was considered using Chi-Square tests. Significance was predetermined at $\mathrm{p}<0.05$. Stata Version 8 was used for the statistical analysis.

\section{Results}

A total of 117 potentially eligible patients admitted at the surgical wards of the Philippine General Hospital were invited to participate in this study. Fourteen were excluded because of the following reasons: a final histopathologic diagnosis of a benign disease $(n=6)$ or history of previous definitive cancer surgery $(n=8) ; 103$ patients were retained in the final analyses.

The profile of the study population is summarized in Table 2. The majority $(63 \%)$ were female with a mean age of 54 years old. Breast cancer patients accounted for one-third of the patient population while gastrointestinal (GI) cancers, including upper GI, hepatobiliary and colorectal cancers, account for almost half. Among these, colorectal malignancies were the most common accounting for onethird of the patients. Most of them had an advanced stage of disease, commonly stage III. On admission, $84 \%$ were either moderately or severely malnourished based on the PG-SGA. Table 3 shows that 86 out of 103 participants were malnourished. Those with comorbidities accounted for $24 \%$ while approximately $23 \%$ had either neoadjuvant chemotherapy or radiotherapy. In this study, only $10 \%$ had post-operative complications.
Table 2. Profile of the Study Population

\begin{tabular}{ll}
\hline \multicolumn{1}{c}{ Patient Characteristics } & Total $\mathbf{n = 1 0 3}$ \\
\hline Age & Mean: 54 years \\
& Range: $18-84$ \\
Gender & \\
Female & $65(63.1 \%)$ \\
Male & $38(36.8 \%)$ \\
Site of tumor & \\
Breast & \\
Colorectal & $32(31.0 \%)$ \\
Genitourinary & $32(31.0 \%)$ \\
Hepatobiliary & $13(12.6 \%)$ \\
Upper gastrointestinal & $8(7.7 \%)$ \\
Thyroid & $8(7.7 \%)$ \\
Soft tissue & $4(3.8 \%)$ \\
Head and Neck & $3(2.7 \%)$ \\
Cancer Stage & $3(3.0 \%)$ \\
\hline & \\
2 & \\
3 & $1(0.09 \%)$ \\
4 & $31(30 \%)$ \\
With co-morbidities & $44(42.7 \%)$ \\
With neoadjuvant chemotherapy & $27(26.2 \%)$ \\
With neoadjuvant radiotherapy & $25(24.2 \%)$ \\
With infection/use of steroids/fever & $18(17.4 \%)$ \\
& $6(5.8 \%)$ \\
With postoperative complication & $7(6.7 \%)$ \\
Major & \\
Minor & \\
\hline
\end{tabular}

Table 3 shows the relationship of nutritional status to the clinical parameters of the patients. Patients with breast cancer tended to have better nutritional status while colorectal cancer patients tended to be more nutritionally depleted on admission. Surprisingly, no significant correlation was found between nutritional status, cancer stage and presence of co-morbidities.

A significant association was seen between the duration of hospital stay and the level of nutritional status of patients on admission. Data showed increasing length of hospital stay among those who were moderately or severely malnourished. Among the well nourished, the mean length of stay was 8 days. This was extended to 14 to 15 days for the moderately and severely malnourished, respectively. In this study no significant association was detected between nutritional status and presence of postoperative complications.

Table 4 presents the relationship of nutritional impact symptoms and nutritional status. The most common symptom was pain. This was true regardless of the level of nutrition. On the other hand, patients who presented with lack of appetite (no appetite), early satiety (feels full quickly), and alteration in taste perception of food ("things taste funny") were significantly more likely to be moderately or severely malnourished. 
Table 3. Nutritional status in relation to pre-operative patient's profile and post-operative course

\begin{tabular}{|c|c|c|c|c|}
\hline $\begin{array}{c}\text { Patient } \\
\text { Characteristics }\end{array}$ & $\begin{array}{c}\text { A } \\
\text { Well- } \\
\text { nourished } \\
\text { N (\%) }\end{array}$ & $\begin{array}{c}\text { B } \\
\text { Moderately } \\
\text { malnourished } \\
\text { N (\%) } \\
\end{array}$ & $\begin{array}{c}\text { C } \\
\text { Severely } \\
\text { malnourished } \\
\text { N (\%) } \\
\end{array}$ & P-value \\
\hline \multicolumn{5}{|l|}{ Age (years) } \\
\hline Mean (Range) & $54.3(23-72)$ & $54.7(18-74)$ & $57.2(31-84)$ & 0.591 \\
\hline $\mathrm{SD}$ & 12.6 & 13 & 11.6 & \\
\hline $18-40$ years & $2(1.9)$ & $7(6.8)$ & $2(1.9)$ & \\
\hline $41-60$ & $9(8.7)$ & $21(20.3)$ & $22(21.4)$ & \\
\hline $61-81$ & $6(5.8)$ & $19(18.4)$ & $15(14.6)$ & \\
\hline \multicolumn{5}{|l|}{ Gender } \\
\hline Male & $6(5.8)$ & $15(14.5)$ & $17(16.5)$ & 0.530 \\
\hline Female & $11(10.6)$ & $32(31.1)$ & $22(21.4)$ & \\
\hline \multicolumn{5}{|l|}{$\underline{\text { Site of primary }}$} \\
\hline$\overline{\text { Breast }}$ & $9(8.7)$ & $15(14.5)$ & $8(7.7)$ & 0.054 \\
\hline Colorectal & $3(2.9)$ & $14(13.5)$ & $15(14.5)$ & 0.292 \\
\hline Genitourinary & $3(2.9)$ & $5(4.8)$ & $5(4.8)$ & 0.756 \\
\hline Hepatobiliary & $1(1.0)$ & $3(2.9)$ & $4(3.8)$ & 0.761 \\
\hline Upper GI & 0 & $3(2.9)$ & $5(4.8)$ & 0.229 \\
\hline Thyroid & $1(1.0)$ & $3(2.9)$ & 0 & 0.280 \\
\hline Soft tissue & 0 & $2(1.9)$ & $1(1.0)$ & 0.662 \\
\hline Head and neck & 0 & $2(1.9)$ & $1(1.0)$ & 0.662 \\
\hline \multicolumn{5}{|l|}{$\underline{\text { Stage }}$} \\
\hline 1 & $1(1.0)$ & 0 & 0 & \\
\hline 2 & $7(6.7)$ & 15 (14.5) & $9(8.7)$ & \\
\hline 3 & $8(7.7)$ & $19(18.4)$ & $17(16.5)$ & 0.122 \\
\hline 4 & $1(1.0)$ & $13(12.6)$ & $13(12.6)$ & \\
\hline $\begin{array}{l}\text { With } \\
\text { neoadjuvant } \\
\text { chemotherapy }\end{array}$ & $4(3.9)$ & $8(7.8)$ & $6(5.8)$ & 0.757 \\
\hline $\begin{array}{l}\text { With } \\
\text { neoadjuvant } \\
\text { radiotherapy }\end{array}$ & $1(1.0)$ & $4(3.9)$ & $1(1.0)$ & 0.503 \\
\hline $\begin{array}{l}\text { With ostomies } \\
\text { on admission }\end{array}$ & 0 & $1(1.0)$ & $2(1.9)$ & 0.525 \\
\hline $\begin{array}{l}\text { With Co- } \\
\text { morbidities }\end{array}$ & $2(1.9)$ & $11(10.7)$ & $12(11.7)$ & 0.307 \\
\hline $\begin{array}{l}\text { With Infectious } \\
\text { disease/fever/ } \\
\text { use of steroids } \\
\text { in last } 6 \text { months }\end{array}$ & $1(1.0)$ & $3(2.9)$ & $3(2.9)$ & 0.959 \\
\hline \multicolumn{5}{|l|}{ With } \\
\hline \multicolumn{5}{|l|}{ complications } \\
\hline Major & 0 & $3(2.9)$ & $2(1.9)$ & 0.766 \\
\hline Minor & $1(1.0)$ & $3(2.9)$ & $1(1.0)$ & \\
\hline \multicolumn{5}{|l|}{ Duration of } \\
\hline Mean (Range) & $7.53(3-14)$ & $14.09(2-58)$ & $15.13(4-60)$ & 0.048 \\
\hline SD & 4.03 & 11.65 & 11.52 & \\
\hline
\end{tabular}

In summary, this study estimates a malnutrition prevalence rate of $84 \%$ among cancer patients at PGH. Among those who are malnourished, $45.6 \%$ were moderately malnourished while $37.8 \%$ were severely malnourished. The most common nutritional impact symptom of patients is pain which was present in more than $50 \%$ of the patients and it is more prevalent among the malnourished group. Other symptoms with a negative impact on nutrition were early satiety, lack of appetite and alteration in taste perception. Those with poorer nutrition have a significant increase in their length of hospital stay (mean $=15$ days) although nutritional status did not show any association with the occurrence of post-operative complications.

Table 4. Relationship of nutritional status with nutritional impact symptoms

\begin{tabular}{|c|c|c|c|c|c|}
\hline $\begin{array}{c}\text { Nutritional } \\
\text { Impact } \\
\text { symptoms of } \\
\text { patients }\end{array}$ & $\begin{array}{c}\text { Total } \\
\text { Number } \\
\text { n (\%) }\end{array}$ & $\begin{array}{c}\text { A } \\
\text { Well- } \\
\text { malnourished } \\
\text { n (\%) }\end{array}$ & $\begin{array}{c}\text { B } \\
\text { Moderately } \\
\text { malnourished } \\
\text { n (\%) }\end{array}$ & $\begin{array}{c}\text { C } \\
\text { Severely } \\
\text { malnourished } \\
\text { n (\%) }\end{array}$ & P-value \\
\hline Nausea & $22(21.4)$ & $2(1.9)$ & $10(9.7)$ & $10(9.7)$ & 0.507 \\
\hline No appetite & $16(15.5)$ & 0 & $5(4.8)$ & 11 (10.6) & 0.013 \\
\hline Vomiting & $3(2.9)$ & 0 & $1(1.0)$ & $2(1.9)$ & 0.525 \\
\hline Constipation & $27(26.2)$ & $2(1.9)$ & $14(13.5)$ & $11(10.6)$ & 0.329 \\
\hline $\begin{array}{l}\text { "Things taste } \\
\text { funny" }\end{array}$ & 14 (13.6) & 0 & $4(3.8)$ & $10(9.7)$ & 0.014 \\
\hline $\begin{array}{l}\text { "Smells } \\
\text { bother me" }\end{array}$ & $7(6.8)$ & 0 & $3(2.9)$ & $4(3.8)$ & 0.370 \\
\hline Diarrhea & $2(1.9)$ & 0 & $1(1.0)$ & $1(1.0)$ & 0.809 \\
\hline Mouth sores & $13(12.6)$ & $3(2.7)$ & $4(3.8)$ & $6(5.8)$ & 0.502 \\
\hline $\begin{array}{l}\text { Problems on } \\
\text { swallowing }\end{array}$ & $8(7.8)$ & $1(1.0)$ & $3(2.9)$ & $4(3.8)$ & 0.761 \\
\hline Pain & $52(50.5)$ & $7(6.7)$ & $22(21.3)$ & $23(22.3)$ & 0.374 \\
\hline No taste & $2(1.9)$ & 0 & $1(1.0)$ & $1(1.0)$ & 0.809 \\
\hline $\begin{array}{l}\text { Feels full } \\
\text { quickly }\end{array}$ & $34(33.0)$ & $1(1.0)$ & $17(16.5)$ & $16(15.5)$ & 0.030 \\
\hline
\end{tabular}

\section{Discussion}

\section{Prevalence of Malnutrition}

Several factors have been identified as reasons for the high prevalence of malnutrition in cancer. These include type of tumor and its location, stage of disease, type of treatment and even psychosocial factors such as family interactions and feelings of isolation of the patient. ${ }^{2}$ The prevalence of malnutrition amongst cancer patients can range from $30 \%$ to $85 \%$, depending upon the site of the malignancy and the measure used. A recent study of the prevalence of malnutrition in different French cancer centers using the PG-SGA showed a $30 \%$ prevalence rate ${ }^{8}$ by simply calculating patient's body mass index and weight loss percentage in the last six months. That the prevalence of malnutrition of all cancer patients combined is as high as $84 \%$ in this study may be attributed to better sensitivity of the scored PG-SGA in detecting malnutrition and to the high proportion of gastrointestinal malignancies of patients in the study. It is also likely at least in part to relate to the advanced stage of disease at which patients in developing countries such as the Philippines are often admitted.9,10 A local study done at a private tertiary hospital in Manila showed a 
similar high prevalence of malnutrition in its cancer center which was $63.6 \% .^{11}$

As expected, those with cancer of the GI tract had a higher incidence of malnutrition. However, even those with non-GI malignancies have high rates of malnutrition implying that many other systemic factors contribute to the nutritional status of cancer patients. Recent researches have looked into the anorexia-cachexia syndrome, a debilitating and even deadly symptom in cancer. This involves loss of desire to eat and involuntary loss of adipose and muscle tissue. Tumor necrosis factor and cytokines hasten proteolysis, lipolysis and disturbances in the central mechanisms that control food intake. ${ }^{12}$ According to the National Cancer Institute, $20 \%$ to $40 \%$ of patients die from complications of malnutrition and not from the malignancy. ${ }^{13}$

\section{Nutritional Impact Symptoms}

Examples of nutritional symptoms include early satiety, anorexia, fat malabsorption with crampy abdominal pain and bloating, nausea, vomiting, diarrhea, constipation, pain or fatigue. These symptoms are treatable but they require early detection and aggressive management. ${ }^{14}$ In this study, a statistically significant association was detected between malnutrition and lack of appetite, early satiety, and alteration of taste perception. Without treatment, these symptoms can hasten patient's deterioration and prevent response to treatment. By identifying these nutritional impact symptoms early in cancer management, simple measures can be done to prevent adverse effects of these symptoms. These include adjusting the taste of food based on patient's preference, providing small but frequent feedings, introducing variety in the menu, encouraging families to include the patient regularly in their dining experience, and allowing patients more active participation in the choice and preparation of their food when possible.

\section{Impact of Poor Nutrition on Patient Outcome}

A known consequence of malnutrition among surgical patients is increased risk of morbidity and mortality. Recent studies have also demonstrated that malnutrition at the time of hospital admission is associated with prolonged hospital stay, poor quality of life and higher cost of hospitalization. ${ }^{15}$ In a local study done among colorectal cancer patients, a direct correlation was seen between the level of malnutrition as determined by the Philippine College of Surgeons Surgical Nutritional Assessment Form and the development of post-operative complications. ${ }^{16}$

Among our study population, those with longest hospital stay were those with GI tract malignancies such as those with upper GI (60 days), colorectal (58 days) and head and neck cancers (43 days). In one study done among ambulatory adult patients, nutritional status became a predictor of length of hospital stay. In that study, several factors were mentioned as reasons for the prolonged hospital stay namely presence of malignancies, admission at surgical ward, more than three days of fasting, increased number of procedures, and in-hospital weight loss of more than 5\%. ${ }^{17}$ Malnutrition was identified by Laky, et al. as a modifiable factor in reducing length of hospital stay. In their recent study among gynecological cancer patients, they used length of hospital stay as a surrogate marker for patient well-being since a prolonged stay is also associated with higher cost and rate of infection. ${ }^{18}$ The results of this study are in line with these previous findings, with moderate or severe malnutrition upon admission being associated with longer stay in the hospital. The average length of stay among the moderately malnourished was 14.09 days (SD = 11.65) and 15.13days ( $S D=11.52)$ among the severely malnourished. The longer period of stay was significantly higher than the 7.53 days among well-nourished patients ( $\mathrm{p}$ $=0.048$ ). In the PGH setting, length of hospital stay is also affected by the patient's financial capabilities and institutional limits such as availability of certain diagnostic or imaging modalities required for pre-operative planning.

That this study did not detect any association between nutritional status and development of post-operative complications may be due to the small number of patients in the study population although it showed a $10 \%$ incidence of post-operative complications.

The strength of this paper is its prospective study design. It utilized the scored PG-SGA tool, a validated nutritional assessment tool for cancer patients, allowing a standardized evaluation of the nutritional status of the study population, as well as their nutritional impact symptoms. The study is, however, limited by a relatively small sample size.

\section{Conclusion}

Using the scored PG-SGA, this study has observed a correlation between severity of nutritional status on admission and increased length of hospital stay among cancer patients at the Philippine General Hospital. The most common nutritional symptoms our patients experience include lack of appetite, early satiety and differences in taste perception. These are also correlated with the degree of malnutrition on admission. Severe malnutrition adversely affects outcomes and so it is important to stratify patients early through routine nutritional assessment. Intervention through nutrition support programs can be used as an important strategy to improve patient outcome, decrease hospital stay and cost.

\section{Acknowledgments}

The authors are grateful to Ms. Joy Sison and Ms. Rheamel Lopez for the assistance in the data collection and statistical analysis. The authors would also like to acknowledge Mr. Hubert Bautista for providing technical and financial support for this study. 


\section{References}

1. Shike M. Nutrition therapy for the cancer patient. Hematol Oncol Clin North Am. 1996; 10(1):221-34

2. Argilés JM. Cancer-associated malnutrition. Eur J Oncol Nurs. 2005; 9 Suppl 2:S39-50.

3. Löser C. Malnutrition in hospital: the clinical and economic implications. Dtsch Arztebl Int. 2010; 107(51-52):911-7.

4. Department of Surgery Philippine General Hospital, Integrated Surgical Information System. 2009. [cited June 2010].

5. Bauer J, Capra S, Ferguson M. Use of the scored Patient-Generated Subjective Global Assessment (PG-SGA) as a nutrition assessment tool in patients with cancer. Eur J Clin Nutr. 2002; 56(8):779-85.

6. Gianotti L, Gentilin O, Braga M. Nestlé Nutr Workshop Ser Clin Perform Programme. Nutrition in oncological surgery. 2000; 4:239-54.

7. Read JA, Crockett N, Volker DH, et al. Nutritional assessment in cancer: comparing the Mini-Nutritional Assessment (MNA) with the scored Patient-Generated Subjective Global Assessment (PGSGA). Nutr Cancer. 2005; 53(1):51-6.

8. Pressoir M, Desna S, Berchery D, et al. Prevalence, risk factors and clinical implications of malnutrition in French Comprehensive Cancer Centres. Br J Cancer. 2010; 102(6):966-71.

9. Ngelangel CA, Wang EH. Cancer and the Philippine Cancer Control Program. Jpn J Clin Oncol. 2002; 32Suppl:S52-61.

10. Laudico AV, Mirasol-Lumague MR, Mapua CA,et al. Cancer incidence and survival in Metro Manila and Rizal Province, Philippines. Jpn J Clin Oncol. 2010; 40(7):603-12.
11. Fernando R, Llido L, Nutrition Management and Support Team Prevalence of malnutrition in a tertiary care hospital in Metro Manila. St. Luke's Medical Journal. 1996; 3(2): 45-51.

12. Laviano A, Meguid M, Inui A, Muscaritoli M, Rossi-Fanelli, F. Therapy insight: cancer anorexia-cachexia syndrome-when all you can eat is yourself. Nat Clin Pract Oncol. 2005; 2(3):158-65.

13. National Cancer Institute at the National Institutes of Health, Nutrition in Cancer Care [Online]. 2011 [cited 2012 March]. Available from http://www.cancer.gov/cancertopics/pdq/supportivecare/nutrition/Healt hProfessional

14. Ottery F. Supportive nutritional management of the patient with pancreatic cancer. Oncology. 1996 September; 10(9Suppl):26-32.

15. Kyle U, Coss-Bu J. Nutritional assessment and length of hospital stay. CMAJ. 2010; 182(17):1831-2.

16. Ocampo R, Camarse C, Kadatuan Y, Torillo M. Predicting post-operative complications based on surgical nutritional risk level using the SNRAF in colon cancer patients: a Chinese General Hospital and Medical Center Experience. Philippine Journal of Surgical Specialties. 2008; 63(4):147-53.

17. Caccialanza R, Klersy C, Cereda E, et al. Nutritional parameters associated with prolonged hospital stay among ambulatory adult patients. CMAJ. 2010; 182(17): 1843-9.

18. Laky B, Janda M, Kondalsamy-Chennakesavan S, Cleghorn G, Obermair A. Pretreatment malnutrition and quality of life - association with prolonged length of hospital stay among patients with gynecological cancer: a cohort study. BMC Cancer. 2010; 10:232.

\section{Acta Medica Pfilippina \\ THE NATIONAL HEALTH SCIENCE JOURNAE \\ का \\ tนт

\section{Acta is now accepting membership}

Privileges of members:

- Allows you to submit articles for possible publication

- Have access to all the articles in the website (archives included) which can be downloaded and printed in pdf format

- Advertise your products/services in the available spaces of the website (for approval of the Editor-in-chief)

For details, please visit our website at www.actamedicaphilippina.com.ph or e-mail us at businessmanager@actamedicaphilippina.com.ph for any questions or queries. 